\title{
Understanding insertion and integration in a study abroad context: The case of English-speaking sojourners in France
}

Kevin McManus, York University, UK

Rosamond Mitchell, University of Southampton, UK

Nicole Tracy-Ventura, University of South Florida, USA

To appear in Revue Française de Linguistique Appliquée 19 (2).

\section{Introduction}

A period of residence in France has played a part in the education of English elites over centuries, for varied reasons (e.g. as part of the 'grand tour' for the aristocracy, or as a means to engage with cutting edge science and philosophy, in the $18^{\text {th }}$ and $19^{\text {th }}$ centuries). From the early $20^{\text {th }}$ century, young people have moved between France and England as language teaching assistants (British Council, 2005), and increasingly undertaken student exchanges. Since 1987, these movements have been rationalised under the umbrella of the European Union Erasmus scheme, which provides financial support for many thousands of young people annually to undertake study or workplace internships abroad across all member states of the Union, with - it is claimed - life-changing consequences (Teichler \& Ferencz, 2011).

Such temporary student sojourns are only part of a much broader movement of migrants which characterises the world in the $21^{\text {st }}$ century, including migration between England and France. However, student sojourners have a number of distinctive characteristics, as described by MurphyLejeune (2002) in her ethnographic study of Erasmus students following a range of different European programmes. Student sojourners are voluntary "strangers", who are not driven by economic circumstances to migrate (though they may anticipate improved economic prospects as a result of their sojourn); they expect their stay to be temporary (i.e. they have an expectation of return to a structured role at home), and of known duration; and students are typically young and still in transition to independent adulthood (e.g. they may never have worked/ have opened a bank account/ have rented an apartment, in their home country). These distinctive characteristics mean that student sojourners may "invest" only limited effort in integration in the new environment and culture, may socialise and find emotional support most easily among fellow international student sojourners, and may see the development of personal agency and independence as their greatest goal while abroad (on this see e.g. Kinginger, 2009, 2010; Meier \& Daniels, 2011; Murphy-Lejeune, 2002; Papatsiba, 2006).

Even among European student sojourners, British students are a particular case. Partly because of the limited foreign language skills most typically achieved in British schools (European Commission, 2012; Tinsley, 2013), they are relatively reluctant to undertake study/ work experience abroad, in non-English-speaking contexts, so that Britain receives many more Erasmus participants than it sends abroad, for example (Teichler, 1997). Those British students who do go abroad are thus a relatively selective group, likely to be characterised a) by relatively high levels of intercultural 
awareness, and b) by a positive motivation to learn languages (e.g. languages students undertaking a year abroad). On the other hand, the widespread currency of English as a lingua franca in contemporary Europe considerably complicates the linguistic landscape they will encounter, considered as a language learning environment.

This paper draws on a recent study of British students of languages undertaking a year abroad in France, in a variety of placements (as language teaching assistants, as exchange students, and as workplace interns). The data were gathered in the context of the 2011-2013 [NAME] project, a larger study undertaken at [a UK university] which investigated both the language learning and social integration of British students spending an academic year abroad in France, Spain or Mexico (more details are given in Section 2 below). Having made a positive choice to specialise in languages at university, and having already reached a relatively advanced level in French during their secondary school education, it could be assumed that these students were positively motivated to further develop their language skills, to deepen their intercultural understanding, and to integrate socially within the local society. Indeed, in pre-departure interviews (in French), the participating students unanimously expressed the wish to integrate and in particular to make French same-aged friends. The paper first of all presents an overview of the range of tools used to gather both quantitative and qualitative data on participants' social integration. The paper then goes on to evaluate the degree of success of even such highly motivated participants in achieving this declared goal, and to consider social, sociolinguistic and personal factors which appear to influence the degree of social integration achieved by individual participants.

\section{Documenting language contact and use in a study abroad context}

\subsection{Quantitative approaches}

Studies examining language use and contact among students sojourning abroad often draw on questionnaire data to get a picture of target language use in study-abroad compared with traditional-classroom contexts. The Language Contact Profile (Freed, Segalowitz, Dewey, \& Halter, 2004) is arguably the most widely used questionnaire to document language contact and use. It is published as two versions (pre-test and post-test) for use before and after a study-abroad project. In addition to background information, the pre-test version includes questions on speaking the target language and how often participants undertake six non-speaking activities (e.g. reading newspapers, listening to songs). The post-test version considerably expands the pre-test with questions on living arrangements as well as how often and for how long 34 activities are done. Because the post-test is recommended for use after returning from study abroad, participants are requested to recall how many hours per day they spent on a particular activity, as the extract in Figure 1 shows (Freed et al., 2004 , p. 354). 


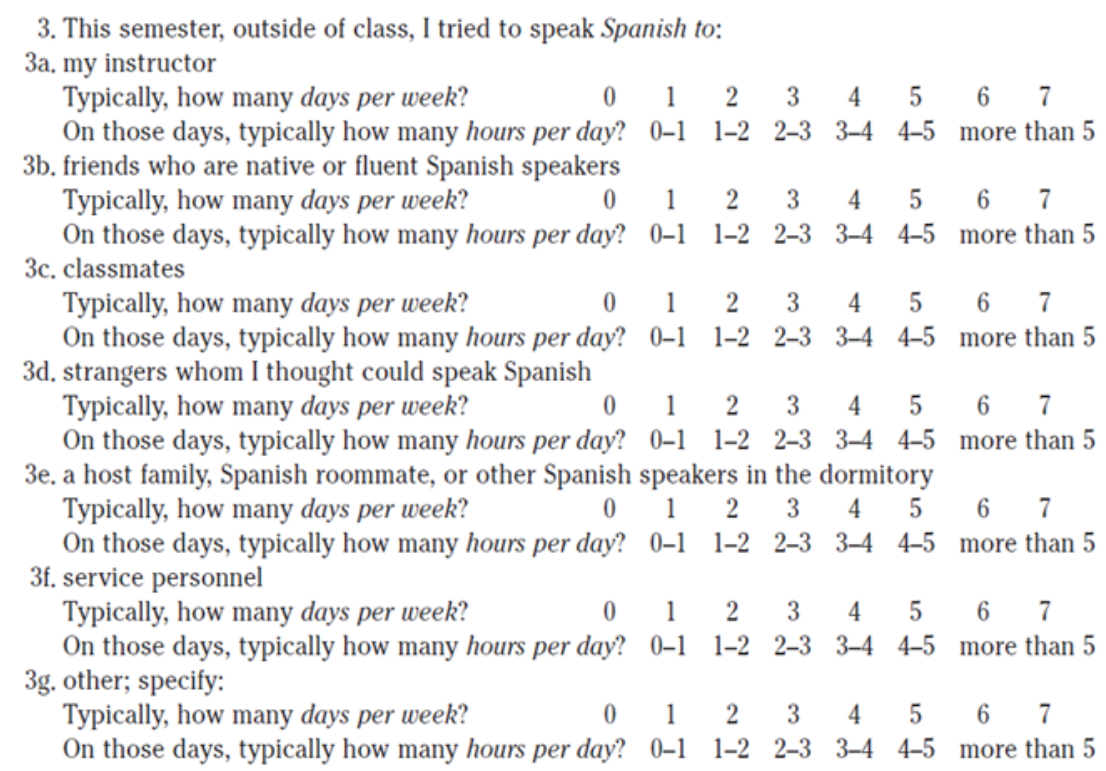

As Figure 1 shows, the Language Contact Profile (LCP) provides a reasonably full list of specified interlocutors from 'strangers' to 'classmates' that participants can use to retrospectively recall speaking patterns. Therefore, when used together, the pre-test can provide a baseline for language contact that can be compared with post-test data to evaluate differences argued to result from study abroad. Furthermore, the LCP has been shown to be adaptable (e.g. Badstübner \& Ecke, 2009; Llanes \& Munoz, 2013). For example, Hernández (2010) and Martinsen, Baker, Dewey, Bown, and Johnson (2010) excluded the pre-test version as well as updating/changing the list of activities. Hernandez (2010) additionally changed the frequency scale from 'days per week' and 'hours per day' to 'hours per week', providing a range from 0.5 to $30+$ hours. Such adaptations indicate that the LCP provides a flexible tool to track language contact influences on second language learning. However, as Kinginger (2011) appears to caution, it is important for researchers to be clear about what their research tools measure. When administered retrospectively, as Freed et al. recommend, the LCP forces participants to generalize their recollections over the entire study-abroad period (12 weeks in many studies) and then quantify language contact instances into hours. The reliability of such reconstructed detail must be seen as questionable and requiring additional validation to be depended upon. In particular, because the LCP requires generalizations over the entire study abroad period, the broad, people-based categories (e.g. 'classmates' see Figure 1) may obscure variation in interaction patterns, depending on when they occur in time. As a result, it seems that despite being one of the staple tools for understanding language contact in study abroad research, additional and/or refined measures are required. In this respect, recent work by Dewey and colleagues offers a promising development (Dewey et al., 2014; Dewey, Ring, Gardner, \& Belnap, 2013). Their research designs typically split language contact into language use and social networks, each documented with a different measure. For language use, the Language Log of Martinsen et al. (2010) requires learners to document their daily use of the target language in minutes for 20 specified activities, as shown in Figure 2. For that study, participants were requested to complete the Log for seven consecutive days (three weeks into the stay). 
Figure 2: Language Log (Martinsen et al. 2010, p.62):

Each day, record the number of minutes that you spend speaking, reading, listening to, or writing in Spanish while engaged in the activities listed below

Language Log

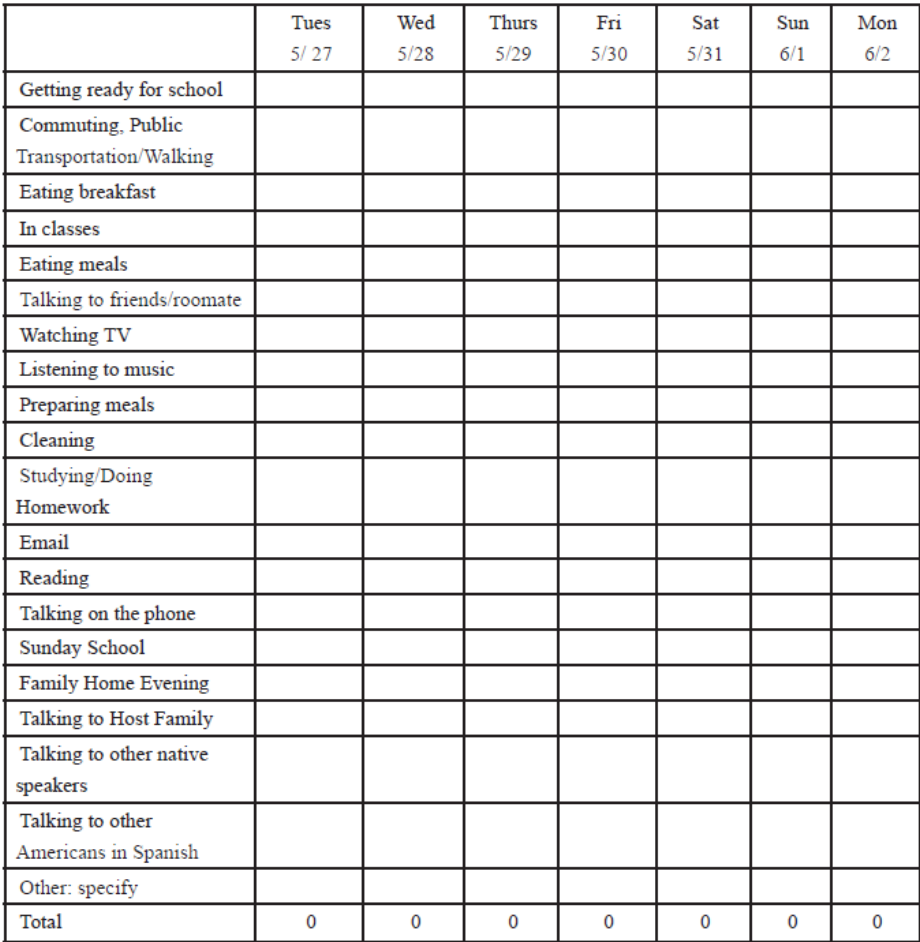

As Figure 2 indicates, analyses of the Language Log typically total the number of minutes for targetlanguage use per day, similarly to the LCP. However, the data is collected much closer to the time period being described, and the tool permits the changing amount of time spent doing particular activities to be compared. For example, Martinson et al. were able to show that during one particular week of their stay participants spent a substantial amount of time "using Spanish productively (i.e., speaking and writing-for example talking to roommates, talking during dinner, etc.)" (p.51), but also that this burst of Spanish use was not typical of the complete stay abroad.

As for the study of social relations and social integration, the Study Abroad Social Interaction Questionnaire (SASIQ; Dewey, Bown, \& Eggett, 2012; Dewey et al., 2013) documents the nature and structure of participants' social networks (Milroy, 1987), including the number of contacts (size) and their closeness (intensity), the frequency of interactions (durability) and the different social groups a participant has (e.g. home group, free-time group). Participants are asked retrospectively to list up to twenty interlocutors with whom they interacted regularly. They are then asked a series of questions about the contact, including to (1) rate level of friendship on a 1-10 scale ( $1=$ acquaintance, 10 = close confidant), (2) how they met and (3) an elaboration of how they met (see Dewey et al., 2013). Wiklund (2002) employed a similar strategy in order to document immigrant children's social networks in Sweden. Her questionnaire primarily focused on the density and multiplexity of participants' social networks, supplemented by information about regular activities. Participants were first requested to list people with whom they regularly interacted from five groups: (1) family, (2) relatives, (3) fellow nationals, (4) Swedes, (5) people from a different ethnic group, but who are not Swedes. Then, for each contact listed, a series of questions followed about 
the frequency and nature of the interactions, including: language(s) used, where, when and how often meet-ups occurred, and the activities done together (up to five activities per contact).

Participants additionally listed three best friends in each of the following groups: own ethnic group, Swedes, different ethnic group, but not Swedes. Interestingly, whilst Wiklund is concerned with many of the same social network constructs as seen in the other tools (e.g. density, durability), her approach avoids asking participants to report in very small measurement units. For example, the LCP and the Language Log ask for fine-grained quantities as indicators of frequency and durability (e.g. minutes, hours), whereas Wiklund has broader categories that appear easier to conceptualize when recalling interactions retrospectively, such as three times a week or more often. In the same vein, Wiklund's three best friends list seems a much easier task to complete than rating all contacts on a 110 friendship scale.

\subsection{Qualitative approaches}

While questionnaires and other quantitative tools have been popular means for attempting to document language contact and use, qualitative methods have also been widely used to study related yet complementary aspects of study abroad. These methods have appealed particularly to researchers interested in the evolution of student sojourners' L2 identity, and the development of intercultural awareness and understanding. Thus for example, Murphy-Lejeune's major study of the social experiences of student participants in various types of Erasmus programme (2002) drew on a set of retrospective in-depth "semi-directive" interviews, which followed the progress of the sojourn abroad (pp. 42-46). Benson et al. (2013) used pairs of pre-sojourn and post-sojourn interviews to develop individual case studies of L2 identity development among Hong Kong students taking part in a range of longer and shorter programmes abroad. Pellegrino-Aveni (2005) accompanied her target group of American students to Moscow, and collected a variety of qualitative data including interviews, student journals and classroom observations, in order to develop ethnographic case studies of her participants. Aguilar Stewart (2010) had her participants maintain weekly e-journals, which documented the extent and development of their social integration in a small Mexican community over time. Researchers concerned with the home stay as a possible route to social integration in the new setting have used a range of qualitative methods including open ended questionnaires, interviews and participant and non participant observation (notably of mealtime encounters), to document the development of $L 2$ identities and social relations with host families (Cook, 2008; Diao et al., 2011; lino, 2006; Schmidt-Rinehart \& Knight, 2004).

\subsection{Mixed method case study approaches}

Other researchers working on SA participants' social integration and/ or intercultural development have adopted more eclectic/ mixed method approaches. Thus for example, understanding social networks is certainly complex (e.g. see reviews in Kadushin, 2012; Scott, 2013), but one way to approach their complexity can be found in combining multiple perspectives, including case study approaches (e.g. Kinginger, 2008). Isabelli-García (2006) used a case-study approach drawing on weekly diaries and social network logs to understand the integration and insertion of four Americans in Argentina. Her participants received seven daily log sheets to document their social networks in terms of density, durability and multiplexity and included questions on the languages used, activities undertaken and the frequency of contact. In order to track change over time, the social network logs were completed at three points during the stay abroad (weeks 1, 8 and 15). The diary entries were used primarily to document learners' social attitudes and motivation whilst abroad, but they also complemented the social network logs by adding different types of information. Aided by a 
complementary qualitative analysis, Isabelli-García (2006) produced pioneering examples of social network change in a study abroad context, and of the factors that can drive social network change over time. For example, one participant (Stan) initially socialized with his American friends because he had few Argentine contacts. He fought to maintain contact with a Spanish-speaking friend of a friend and over time gradually met more Spanish speakers as a result. This particular social network is illustrated in Figure 3 (from Isabelli-García 2006, p.243)

\section{Figure 3: Social network structure for Stan}

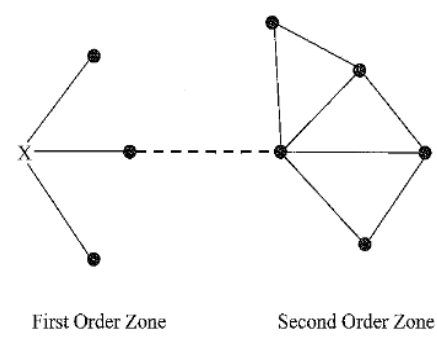

Figure 3 shows that Stan (represented by $x$ ) is introduced into a Spanish-speaking network via afriend of a friend (dotted line). Stan then begins to meet other Argentines at various social events and activities through the friend of a friend. As Isabelli-García shows, therefore, mixed method case study approaches offer the potential to contribute to our understanding of integration and insertion by focussing in on individuals and their stories. Similarly, Jackson has conducted a series of mixed method studies tracing the intercultural and identity development of Hong Kong students undertaking SA in Anglophone countries, using interviews, journals, questionnaires, student projects and in-country meetings and debriefings, resulting in rich individual case studies (Jackson, 2008, 2010). Kinginger (2008) conducted a year long study of 24 American students undertaking SA in France, which combined interviews in-sojourn, participant observation and questionnaires with formal language assessments. Her report includes general findings for the group as well as a number of in depth case studies of individual participants, seeking to relate relative language learning success to identity development and social engagement.

\section{The study}

\subsection{Overview of the [NAME] project and research questions}

The [NAME] project aims to develop a coherent and in-depth view of language contact and use and combines multiple methods to understand integration and insertion in a student residence abroad context. A key feature of the [NAME] study was the underlying assumption that residence abroad is no longer a straightforward "immersion" experience, either linguistically or socially, for Anglophone students at least (Kinginger, 2009; Aguilar Stewart, 2010). Rather, it must be seen as a multilingual and intercultural experience, where the continuing roles of the home language and of previously established social relations need to be understood alongside new linguistic and social experiences, including the negotiated use of both English and French as lingua francas (Behrent, 2007; Kalocsai, 2011). With data collected before, during, and after residence abroad, a series of questionnaires (social networks, language engagement and personality) and interviews as well as focused language tests were used in combination to understand the temporary international sojourns of UK students, and their sociocultural and linguistic characteristics and consequences. In this paper, we draw on [PROJECT NAME] French data to address the following questions: 
- What activities do learners of L2 French regularly engage with in a study abroad context?

- Which activities are the most and least frequent?

- Do certain languages $(L 1, L 2)$ influence engagement with particular activities?

- What is the make-up of learners' social networks whilst abroad?

- What languages are used with whom, and in what contexts?

- How do different social contexts influence the choice of contacts, and choice of language $(\mathrm{L} 1, \mathrm{~L} 2)$ ?

- What are learners' strongest social ties, and what languages characterize learners' most regular interactions?

\subsection{Method}

Participants: The [PROJECT NAME] participants discussed in this paper were 29 advanced-level university learners of French, spending Year 3 of a four-year languages degree programme in France. Participants' mean age was 20.5 (range: 19-25) and the mean length of time previously spent studying French was 10.5 years (range: 6-20 years). Participants were assigned to sixteen different regions of mainland France and were all engaged in one of three placement types: teaching assistantship ( $n=15)$, work placement $(n=6)$ and university study $(n=8)$.

Instruments: Two questionnaires were specially designed by the [PROJECT NAME] team to collect information on participant's language engagement and social networks. Both questionnaires took the LCP as starting point, but took into account the criticisms of this instrument discussed above, especially concerns about the degree of precision possible in participants' recollections of social interactions. The language engagement questionnaire (LEQ) was used to document participants' language engagement $(L 1, L 2, L 3)$ for a range of typical year abroad activities. Participants begin by indicating which languages they use on a regular basis (English, French, Spanish, other) ${ }^{1}$. For each language selected, participants are provided with a list of 26 activities and are asked to indicate how often they do each activity in that language on a 5 point scale, choosing from: every day, several times a week, a few times a week, rarely, never. Participants are additionally given the option to comment/reflect on their answers, for example to report whether they read a particular magazine, watch a particular TV/radio programme, or if the TV/radio is often on in the background although they may not be actively watching/listening. Figure 4 is an extract from the LEQ.

\footnotetext{
${ }^{1}$ When a participant selects other they are prompted to specify the language (e.g. German)
} 


\section{French Questions}

\section{Question 1. \\ How often do you do the following in FRENCH?}

\begin{tabular}{|c|c|c|c|c|c|c|}
\hline & everyday & $\begin{array}{c}\text { several } \\
\text { times a } \\
\text { week }\end{array}$ & $\begin{array}{c}\text { a few times } \\
\text { a week }\end{array}$ & $\begin{array}{c}\text { couple } \\
\text { times a } \\
\text { month }\end{array}$ & rarely & never \\
\hline watch television & (-) & O & ○ & O & O & O \\
\hline watch films & (c) & ○ & O & O & O & ○ \\
\hline browse the internet (eg. read news, etc) & (c) & ○ & O & O & (0) & 0 \\
\hline use social networking sites (eg. Facebook/Twitter) & (-) & ○ & ○ & 0 & ○ & ○ \\
\hline read emails & (-) & $\odot$ & ○ & ○ & ○ & ○ \\
\hline write emails & (2) & ○ & ○ & ○ & ○ & ○ \\
\hline listen to music & (-) & ○ & ○ & ○ & ○ & ○ \\
\hline listen to talk radio & (อ) & O & O & 0 & 0 & O \\
\hline
\end{tabular}

The Social Networks Questionnaire (SNQ) was used to collect information about participants' social networks, in particular their regular contacts in different social contexts (work/university, organized free time, general free time, home, virtual social activities). For each context, participants listed people with whom they interacted regularly/had had active contact over the past month. For each person listed, there was a series of follow-up questions:

1. How often do you interact with this person?

- Every day

- Several times a week

- A few times a week

- A couple of times a month

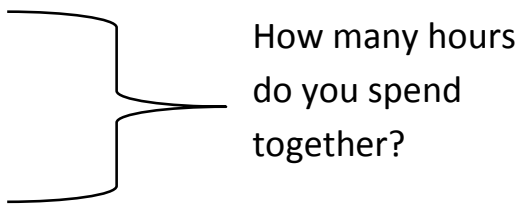

2. What language(s) do you use when communicating with this person?

- French

- English

- Spanish

- Other

- Mixture - > specify which and approximate proportions

3. What is your relationship to this person?

4. How did you first meet?

Participants received the same questions for each person listed and the same questions were asked in each context. Additional questions were included for organized free time (what is the organized activity you do together, e.g. attend church, gym?) and virtual social activity (what type(s) of social virtual activity do you use, e.g. Facebook, Skype, MSN?). Before completing the SNQ, participants were made aware about the questionnaire's purpose because it was thought that the types of 
question may not have been typical to them. In particular, they were told that the same person can appear in multiple contexts and that this would not be unusual. After all the contexts had been completed, participants were asked to list their 'top 5' who were the five people with whom they interacted with the most across all contexts. Lastly, participants were able to leave additional comments if they wanted (e.g. no people listed in home because lived alone). Figure 5 is an extract from the SNQ.

Figure 5: Extract from the Social Networks Questionnaire

\section{Work/Uni Context, Person 1}

These questions refer to the person below:

Kevin

Question 1.
How often do you interact with this person?
\begin{tabular}{l} 
every day \\
\hline several times a week \\
\hline a few times a week \\
\hline a couple times a month
\end{tabular}

\section{Question 2.}

What language(s) do you use when communicating with this person?

Please select $\checkmark$

\section{Question 3.}

What's your relationship to this person?

\section{Question 4.}

How did you first meet? (e.g., through a mutual friend, at work, etc. -- just a brief response)

Interviews: The main qualitative data gathering tool used in the [NAME] project was the semistructured interview (Dörnyei, 2007, Ch 6), conducted face to face in French by a member of the research team at every data collection point (including three visits during the sojourn abroad). These individual interviews had a dual purpose, providing extended interactive speech samples which were used to assess participants' developing fluency and accuracy in speaking French, but also providing substantive information about participants' experiences and activities in France. Set topics covered daily life and work, social relationships, striking incidents, and hopes for the rest of the stay (replaced in the final interview by a question concerning advice to future students). Question wording might vary, and there was limited follow-up questioning, so that participants had considerable control over how fully they answered; they were also aware of the role of the interviews as a source of linguistic data. Overall, it is likely that participants' self-presentation in the 
interviews was affected partly by their level of personal confidence as French users, and also by their perceptions of their interlocutors as representatives of the home university. Nonetheless, cross checking of material from the three different visits, and triangulation with questionnaire data, as well as with a 'reflective interview' conducted in English after return from the year abroad, shows that participants did report meaningfully on many aspects of the year abroad experience, including on the extent and nature of the social relationships developed while abroad, and their overall sense of social integration in France.

\subsection{Procedure and analysis}

The project lasted 23 months, with six data collection points scheduled before, during and after residence abroad. The Pre-test took place in the U.K. (May 2011). Once abroad, participants were visited three times (November 2012, February 2012, and May 2012); two post-tests took place in the U.K. following participants' return (September 2012, January 2013). The LEQ and the SNQ were both conducted at each of Visits 1-3 abroad. They were administered electronically using the questionnaire design tool I-Survey. The questionnaires were completed by the participants in the presence of a member of the research team, who also conducted (and audiorecorded) the semistructured interview, which typically lasted c 20 minutes.

For the questionnaire analysis, data were converted as follows. In order to compare differences in language engagement over time and between different languages, the frequency labels (e.g. Every day) in the LEQ were converted to a numerical scale as shown below:

- Every day $=5$

- Several times per week $=4$

- A couple of time per week $=3$

- A few times per month $=2$

- Rarely $=1$

- $\quad$ Never $=0$

The LEQ analysis used mean group scores to calculate reported engagement with a particular activity with reference to (1) change over time and (2) differences between languages. Paired-samples ttests were used to compare language engagement scores for the group overall, on successive occasions. For the SNQ, the first analysis focused on network size, which involved calculating the number of contacts a participant reported at each data collection point (Visits 1-3), as well as information about language(s) used. The second analysis was more detailed and calculated the number of contacts in each social context (work/university, organized free time, general free time, home, and virtual) as well as languages used. This analysis is presented for each visit to show change over time. The third analysis for network size compared language use across the different social contexts at the same point in time. Finally, results from participants' Top 5 were used to show the most frequent interactions at each data collection point. These data are presented as percentage group means in terms of language(s) used.

To facilitate linguistic analysis, the semi-structured interviews were first of all transcribed orthographically using CHAT conventions (MacWhinney et al., 2000). For content analysis, they were imported into the qualitative data analysis software NVivo, and coded thematically, e.g. identifying all mentions of housemates, colleagues, family, and local, international and home friends, as well as all accounts of leisure activities, of service encounters, and of problem solving. Findings from the interview analysis regarding the impact of placement types on social engagement, and the overall 
evolution of personal relationships during the year abroad in France, are being reported in detail elsewhere (AUTHOR 2, Forthcoming 2015; AUTHORS, Forthcoming 2015). In this paper, these analyses are drawn upon to provide fuller interpretations of the quantitative questionnaire results, and also to illustrate variability within the French L2 participant group.

\section{Results}

\subsection{Language engagement and social practices}

Research question 1 focused on language engagement and whether there were differences over time and between different languages for different language-related activities. Table 1 shows the most frequent activities in French and English over time, for the group overall. The comparisons with English allow us build a comparative picture of language practices, across the two languages. These results show small talk is a frequent activity in both languages occurring at the high frequency end of the scale (everyday - several times a week). Furthermore, although t-tests ${ }^{2}$ showed no statistically significant changes over time for amounts of small talk in either language, small talk in French is significantly more frequent than in English at V1 ( $p=.01)$, V2 $(p=.03)$ and V3 ( $p=.00)$. In contrast, and unsurprisingly, service encounters are frequent in French, but not in English, though they are reported to dip significantly at V2 when compared with V3 $(p=.02)$. Comparisons with service encounters conducted in English reveal that they are significantly more frequent in French at all data collection points $(p=.00)$. However, not all activities exhibit language-based differences. For instance, the between-language and within-language differences over time are not significant for long casual conversations, suggesting similarity between both languages for this activity. Interestingly, both reading and writing text messages are reported to be significantly more frequent in English at V1 $(p=.01)$ and $V 3(p=.05)$, which are the two data collection points that coincide with imminent movement away from home (V1) and toward home (V3). Furthermore, browsing the internet is also reported to be significantly more frequent in English than in French across all data collection points $(p=.00)$, though over time, this activity appears to increase slightly for French and reduce slightly for English.

Table 1. Group mean scores for the most frequent activities reported in French with equivalent English scores ${ }^{3}$

\begin{tabular}{|c|c|c|c|c|c|c|}
\hline Activity & \begin{tabular}{|ll} 
V1 & \\
& French
\end{tabular} & English & ${ }^{\text {V2 }}$ French & English & V3 & English \\
\hline Small talk & 4.83 & 4.14 & 4.66 & 4.25 & 4.61 & 3.82 \\
\hline Service encounters & 4.46 & 0.66 & 4.03 & 0.82 & 4.54 & 0.68 \\
\hline Long casual conversations & 4.07 & 4.38 & 3.79 & 4.11 & 3.79 & 3.93 \\
\hline Browse internet & 3.83 & 4.90 & 3.79 & 4.79 & 3.93 & 4.75 \\
\hline Read text messages & 3.79 & 4.52 & 3.86 & 4.25 & 3.79 & 4.32 \\
\hline Write text messages & 3.76 & 4.55 & 3.83 & 4.22 & 3.79 & 4.32 \\
\hline
\end{tabular}

The least frequent activities conducted in French were also analysed to see whether there were differences over time (e.g. do infrequent activities in French change?) and whether activities in

\footnotetext{
${ }^{2}$ See Appendix $B$ for results showing paired-samples t-tests

${ }^{3}$ Note: 5 = Everyday, 4 = several times per week, 3 = couple of times per week, 2 = few times per month, $1=$ rarely, $0=$ never
} 
French were also infrequent in English. The results indicate that writing for leisure (e.g. diaries, blogs) is extremely infrequent in French (never/rarely), but it is significantly more frequent in English (a few times per month) at all data collection points ( $p=.00$ ). Long phone conversations ( $>5$ mins) and instant messaging (e.g. Facebook chat) are also significantly more frequent in English than in French at all data collection points ( $p=.01$ ). Organized social activities (e.g. clubs, church) appear different to the other French activities reported because they become significantly less frequent over time (between V2 and V3, $p=.02$ ). Interestingly, some activities are relatively infrequent in both languages, such as reading academic texts, reading literature (e.g. fiction), watching TV and watching films. In all these cases, the between-language differences are non-significant.

Table 2. Group mean scores for the least frequent activities reported in French with equivalent English scores

\begin{tabular}{|c|c|c|c|c|c|c|}
\hline Activity & $\begin{array}{l}\text { V1 } \\
\text { French }\end{array}$ & English & V2 & English & $\begin{array}{l}\text { V3 French } \\
\quad\end{array}$ & English \\
\hline Write for leisure & 0.45 & 2.07 & 0.66 & 2.00 & 0.46 & 1.54 \\
\hline Long phone conversations (>5 mins) & 1.31 & 2.66 & 1.55 & 2.61 & 1.61 & 2.93 \\
\hline Watch films & 2.07 & 2.00 & 2.00 & 2.00 & 1.93 & 2.04 \\
\hline Use instant messaging & 2.17 & 3.48 & 2.55 & 3.57 & 2.32 & 3.32 \\
\hline Read academic texts & 2.17 & 1.76 & 2.83 & 2.75 & 2.18 & 1.86 \\
\hline Watch television & 2.24 & 2.93 & 2.31 & 3.07 & 2.25 & 2.93 \\
\hline Read literature & 2.34 & 2.55 & 2.21 & 2.36 & 2.29 & 2.29 \\
\hline Organised social activities & 2.48 & 0.86 & 2.14 & 0.61 & 1.64 & 0.46 \\
\hline
\end{tabular}

The qualitative interviews shed some further light on these bilingual patterns of language use, and help to relate them to participants' social practices and social relations. In particular the interview data make it clear that electronic media are used for different purposes in French and English. In French, these media are used partly to develop and sustain new French-using social relationships, e.g. with new romantic partners, but also extensively for work and study purposes. In English however, electronic media are used as a prime means for sustaining very active contact with family and pre-sojourn friends (who might be back in England, or classmates spending a year abroad elsewhere). Participants experiment to some degree with French TV and cinema, but also keep up with old favourites on British TV through iPlayer and similar tools. The interview analysis also helps to explain why the most frequent French-using activities reported by the group overall are service encounters and casual conversation. This analysis shows clearly that while year abroad placements provide regular opportunities for structured contact with French users (teachers in schools, classmates and instructors at university, work colleagues on work internships), such contact does not routinely lead to friendships offering intimacy and mutual emotional support, and only a minority of participants in France (12/29) achieved such friendships with French users. (For detail on this see AUTHOR 2, forthcoming 2015.) Thus it is unsurprising that long casual conversations, texting, and long phone conversations are less frequent in French than in English (and in the case of the last, even very unusual in French).

\subsection{Social networking and social integration}

Research question 2 focused on learners' social networks, in particular the number of contacts participants reported (network size), the languages used and whether there were changes over time 
as well as differences between social contexts (e.g. work compared with home). Table 3 reports the number of contacts for the group overall, as well as the languages used. This analysis allows us to get an overview of the size of participants' networks. For example, it shows the total number of contacts reduces over time and that the total number of contacts involving English reduces the most (between Visit 1 and Visit 3, there was a reduction of 96 contacts for English users and EnglishFrench mixed users combined). Table 3 indicates that almost 50\% of the group's total network is constituted by English contacts (and more when English-French mix is added). However, when we look more closely in terms of the contacts in each social context (Table 4), we see a high concentration of English contacts in virtual contexts (i.e. internet-based communication). Indeed, language use in virtual contacts is almost entirely with English contacts (>85\% at each visit).

Therefore, although participants' networks seem to be heavily constituted by English contacts, we understand that to a considerable extent this is because of internet-based communication. Table 5 additionally shows that work/university and organized free time contexts appear to most frequently involve French contacts, perhaps unsurprisingly, whereas home life seems to be somewhat balanced between English and French. However, the reported contacts in the general free time category seem to be predominantly English-using.

Table 3. Reported number of contacts with language(s) used over time (whole group)

\begin{tabular}{|c|c|c|c|c|c|c|}
\hline & $\begin{array}{ll}\text { V1 } & \\
& \%\end{array}$ & $\mathbf{n}$ & $\begin{array}{ll}\text { V2 } & \\
& \%\end{array}$ & $\mathbf{n}$ & $\begin{array}{ll}\text { V3 } & \\
& \%\end{array}$ & $\mathbf{n}$ \\
\hline French & 32.2 & 171 & 36.1 & 174 & 36.7 & 153 \\
\hline English & 47.5 & 252 & 47.9 & 231 & 48.2 & 201 \\
\hline French-English Mixture & 20.3 & 108 & 16 & 77 & 15.1 & 63 \\
\hline TOTAL & 100 & 531 & 100 & 482 & 100 & 417 \\
\hline
\end{tabular}

Table 4. Reported number of contacts with languages used in each social context over time (whole group)

\begin{tabular}{|c|c|c|c|c|c|c|c|c|c|c|c|}
\hline & & \multicolumn{2}{|c|}{ Work/Uni } & \multicolumn{2}{|c|}{$\begin{array}{c}\text { Organized free } \\
\text { time }\end{array}$} & \multicolumn{2}{|c|}{$\begin{array}{c}\text { General free } \\
\text { time }\end{array}$} & \multicolumn{2}{|c|}{ Home } & \multicolumn{2}{|c|}{ Virtual } \\
\hline & & $\%$ & $\mathbf{n}$ & $\%$ & $n$ & $\%$ & $n$ & $\%$ & $\mathrm{n}$ & $\%$ & $\mathbf{n}$ \\
\hline \multicolumn{12}{|c|}{ V1 } \\
\hline & French & 49.4 & 76 & 64.9 & 24 & 26.8 & 34 & 35.3 & 24 & 9 & 13 \\
\hline & English & 14.2 & 22 & 13.5 & 5 & 57.5 & 73 & 38.2 & 26 & 86.9 & 126 \\
\hline & Mixture & 36.4 & 56 & 21.6 & 8 & 15.7 & 20 & 26.5 & 18 & 4.1 & 6 \\
\hline & TOTAL & 100 & 154 & 100 & 37 & 100 & 127 & 100 & 68 & 100 & 145 \\
\hline \multicolumn{12}{|c|}{ V2 } \\
\hline & French & 47.4 & 63 & 63.4 & 26 & 37.1 & 49 & 44.8 & 26 & 8.5 & 10 \\
\hline & English & 21.8 & 29 & 14.6 & 6 & 49.2 & 65 & 43.1 & 25 & 89.8 & 106 \\
\hline & Mixture & 30.8 & 41 & 22 & 9 & 13.7 & 18 & 12.1 & 7 & 1.7 & 2 \\
\hline & TOTAL & 100 & 133 & 100 & 41 & 100 & 132 & 100 & 58 & 100 & 118 \\
\hline \multicolumn{12}{|c|}{ V3 } \\
\hline & French & 54.2 & 64 & 74.1 & 20 & 30.2 & 35 & 42 & 21 & 12.3 & 13 \\
\hline & English & 17 & 20 & 11.1 & 3 & 55.2 & 64 & 46 & 23 & 85.8 & 91 \\
\hline & Mixture & 28.8 & 34 & 14.8 & 4 & 14.6 & 17 & 12 & 6 & 1.9 & 2 \\
\hline & TOTAL & 100 & 118 & 100 & 27 & 100 & 116 & 100 & 50 & 100 & 106 \\
\hline
\end{tabular}


It is worth looking at the proportion of English and French contacts across the different social contexts at the same point in time as well, as shown in Figure 5 for English at Visit 3. This confirms the general conclusion that English contacts are most frequently found in virtual and general free time contexts, with fewer English contacts in home, work/university and especially organized free time contexts. This picture contrasts with Figure 6 (French contacts at Visit 3), which shows that French contacts are most frequently found in work/university contexts and general free time, with the fewest reported numbers of French contacts found in home, organized free time and virtual contexts. Taking Table 4 and Figures 5 and 6 together, we can see that contacts using French are in the majority to be found at work/university, followed by the general free time context. In contrast, contacts that use English are in the majority to be found in virtual and general free time contexts.

\section{Figure 5. Reported number of contacts with English in each social context at V3}

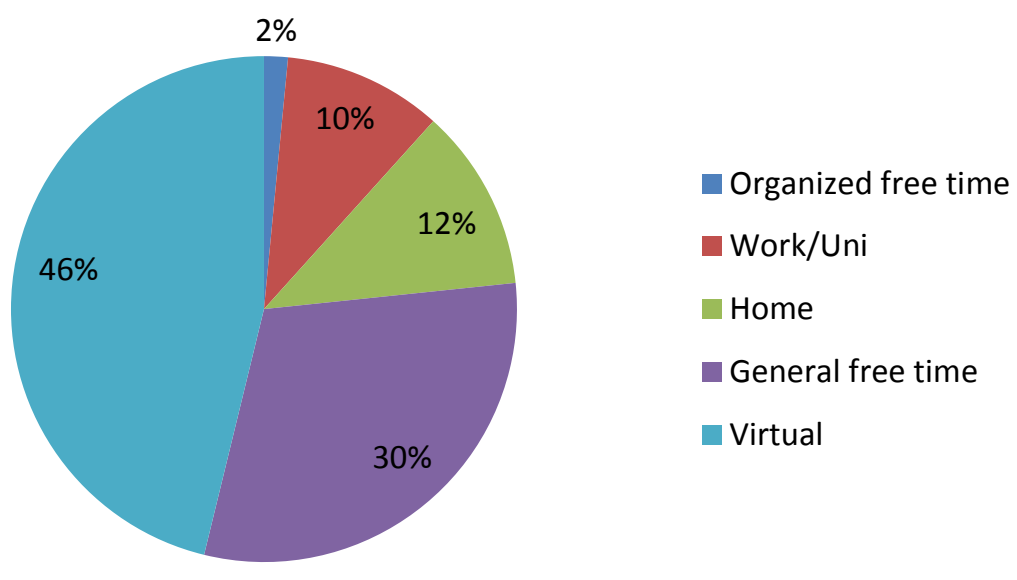

Figure 6. Reported number of contacts with French in each social context at V3

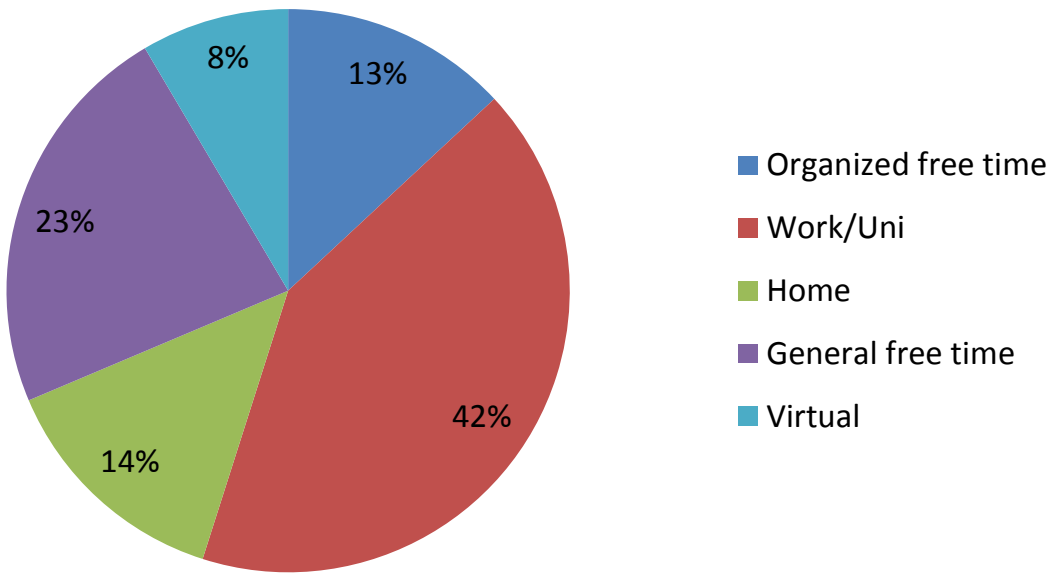

The results for participants' Top 5 contacts also tend to confirm the enduring dominance of English using contacts. . The Top 5 are the five people with whom participants interacted the most across all contexts. Figure 7 shows the distribution of all the people nominated as Top 5 by French group 
members, and shows that at all visits English-based contacts are the most frequent, especially at Visit 3 (the moment of return to home for many), where English-based contacts represent $60 \%$ of the groups' Top 5 contacts.

\section{Figure 7. Top 5 with language(s) used}

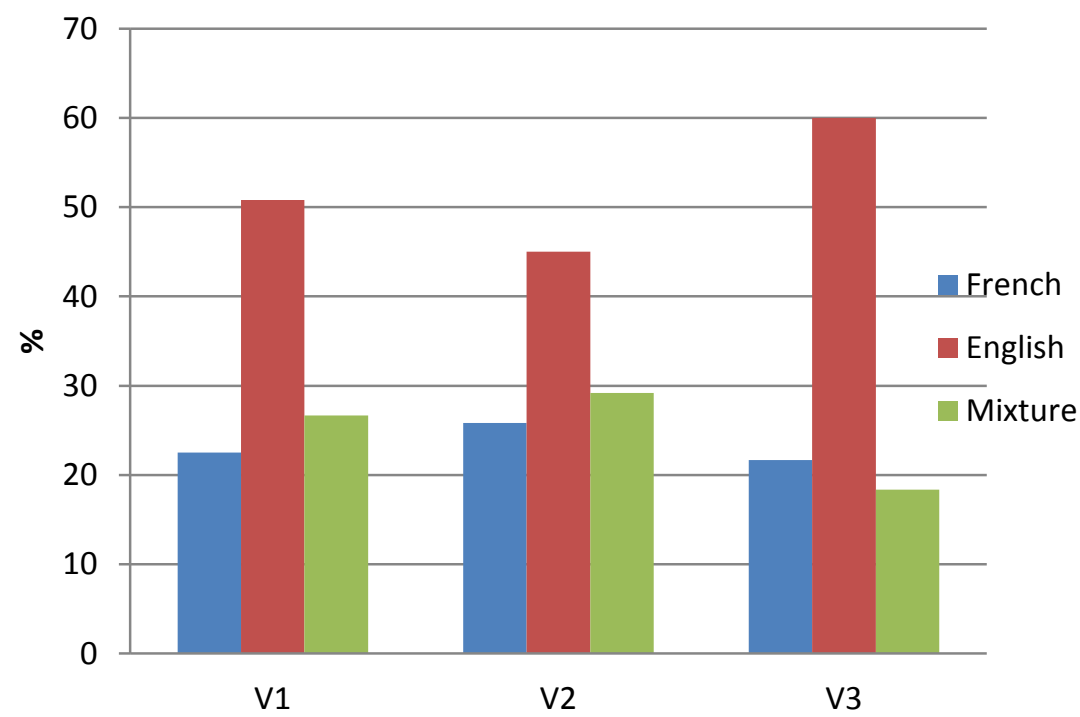

The qualitative interview findings again shed further light on the quantitative picture deriving from SNQ findings. They confirm the crucial importance of work or university as a site for daytime organised contact with French users, involving socialising in staffrooms, or in workplace or campus cafeterias, as well as professional relationships conducted in the classroom or office (that is, provided the early linguistic difficulties reported by many participants, which initially made them somewhat unrewarding as conversational partners, could be overcome). At the same time, as we have seen, they confirm the use of virtual media as a key means to sustain pre-sojourn social relationships with family and home friends. Regarding in-sojourn domestic networks, the interviews report some variety of settings and housemates. The most typical domestic setting while abroad was some form of institutional residence (e.g. a university or school campus residence), typically shared with other international peers (fellow students or assistants). In these settings, French could be used as shared lingua franca alongside English (on this see also Behrent, 2007). However quite a few participants in France shared apartments with one or two others, who were most usually Englishspeaking. A minority lived with French families or flatmates; in stable family settings, rewarding relationships with French users and exciting cultural adventures could result, but when subletting from a French coeval, relationships could and did sometimes break down, with claims of harassment, fraud etc. Thus the 'balanced' picture provided by the group statistics, of equal amounts of French and English contacts at home, is somewhat misleading, and individual experiences in this respect were quite diverse.

Regarding general leisure time, the interviews documented clearly the ease and speed with which participants gained access to peer international networks when in France, e.g. through induction events for language assistants, or through Erasmus Facebook pages and organized events. This instant networking was welcomed by most participants, as providing emotional support, and helping reduce homesickness and/ or culture shock (even though some recognized that their chances of 
making local French friends might be reduced if they adopted such a strong Erasmus identity). Members of these networks (sometimes including peers from the home university) continued as participants' most frequent companions when 'going out' to bars etc. locally, or when undertaking touristic travel in the region or beyond. Family and friends from England were also reported as fairly frequent visitors to France, who of course also expected to join participants in touristic activity.

Some participants who started the year embedded in Erasmus networks nonetheless gained access to local French contacts with whom to spend their leisure time, as time progressed. This happened in different ways. A small number of female participants found French boyfriends, through whom they gradually met wider circles of locals. Some of those living with French families found contacts with similar interests, which led to activities outside the family. And a small number did eventually find local friendships through work or study (e.g. when a language tandem partner, or a fellow intern, turned into a friend).

However, the participants who most successfully developed local contacts (other than with boyfriends) were those who reported rejecting or bypassing most Erasmus networking, and also had a skill of some kind to attract local interest. For this minority group, organized leisure activity (music, sport, a fashion show) opened doors to friendships and to other types of leisure spent in company with locals (i.e. general free time). Participant 108, for example, was an exchange student who described visiting her target city early in the summer, so as to make sure of a French flatshare before the academic year began; her landlady became a year-long mentor and friend. On campus, she joined a local students' charity club, and avoided Erasmus students apart from one Asian girl with whom she spoke only French as lingua franca, and who became a close friend. Outside the university, she joined a local athletics club, and became intimately involved in its activities as both a competitor and supporter, making strong friendships with her coach, and with fellow club members. Participant 129 (exchange student) described producing her clarinet and playing it in the residence kitchen at the start of her sojourn; she quickly met many musicians and spent evenings regularly playing at folk music sessions around the city and beyond. Participant 102 (a workplace intern) immersed himself in the technical work of the IT team at his workplace, and gained respect because of his strong technical contribution.

In summary, the results for language engagement have shown differences for English and French use on a range of language-related activities indicating that certain activities appear to promote French (e.g. service encounters, organized social activities), some appear to be conducted in both languages with similar degrees of frequency (e.g. watch films) and some of the less frequent activities overall are comparatively more frequent in English than French (e.g. long phone conversations, writing for leisure). Furthermore, many of these findings are supported by the SNQ results, and also by the interview results. For example, English-based contacts appear to dominate in virtual social contexts, whereas French-based contacts are found most frequently in work/university contexts (see Table 4). The SNQ also indicated that general free time appears to be a social context shared by French- and English-based contacts in similar proportions. The Top 5 results additionally showed that most frequent interaction was reported to be with English-based contacts. The interviews show how these overall group statistics derive from a wide variety of individual predispositions, opportunities and practices, which lead to very different social network structures for individual participants. 


\section{Discussion and conclusions}

From a methodological point of view, the work presented in this paper shows clearly the necessity to approach contemporary study/ residence abroad as a multilingual and intercultural experience, involving virtual as well as face to face relationships, and the maintenance of long term social relations alongside those created during the sojourn itself. A research approach which studied only participants' social uses of French, and their networking with local people, would produce a seriously distorted understanding of their everyday linguistic and social practices. The work also shows the benefits of mixed method research, using a range of complementary tools to document these practices as they evolve over time, but also to interpret and explain these.

In terms of substantive findings, the evidence shows that almost all participants achieved a degree of integration through their assigned roles in their workplace or classrooms, which together with internet use, provided rich access to French. However, even such a well motivated and interculturally sensitive group of year abroad participants evidently had difficulties with bringing this integration to the higher level that they themselves had imagined and desired before departure, i.e. forming personal friendships with coevals. Almost universally, in the Visit 3 interviews, participants expressed self criticism about this, and advised future year abroad participants to make "more effort" to make French friends. However, the data presented allows identification of structural factors which confront the student sojourner, and place barriers in the way of intimacy with locals. During the first days of arrival, with fear of homesickness and culture shock, fellow sojourners offer important emotional, social and practical support. International networks thus emerge very quickly, and continue to provide satisfying support for many, when pursuing a touristic and leisure agenda. Family and pre-sojourn friends are also immediately available on the internet, and two way visiting also reinforces these longstanding relationships. Thus loneliness is avoided, and many novel practical problems are solved in solidarity with other sojourners. On the other hand, these instant networks may initially repel local coevals (who in any case have strong existing networks).

The substantial minority of participants who moved beyond international networks to form closer local relationships did so in varied ways. For most, this was a gradual process (the girl who found a long term French boyfriend in the first week, was very much the exception). It seemed that personal agency could impact on the local social structures of sojourners' placements, where individual participants had a valued skill to offer, together with the linguistic capability, confidence and initiative to capitalise on this. And once started, networking with locals could snowball (meeting families and friends of fellow interns, boyfriends or host families, for example), though again at varying pace. We have already described how the self-confident participant 129 broke quite quickly into folk music networks in her university city, having made an initial contact in her résidence universitaire. However, participant 104 moved much more slowly and cautiously, with encouragement from his host family, gradually discovering choirs he could join, and eventually enrolling in the local Conservatoire de Musique, so that after several months he could claim in interview to know pretty well the whole music scene in his particular city.

Of course, in addition to musical, artistic or sporting talent, participants found that their English language proficiency could also be an attractive trait to locals, which could be exploited to set up language tandems or language tutoring (in turn sometimes leading to new friendships). Tensions could ensue, between the development of friendships and sojourners' intentions to use and to learn French - it is clear from interview that some friendships with local French coevals were conducted 
largely through the medium of English (and that a few relationships actually broke down over this issue).

Finally, as noted earlier, five female participants found French boyfriends and formed long lasting relationships with them (some apparently set to continue post-sojourn, and starting to involve wider family networks). Unfortunately how these relationships began was not typically described, but again it can be assumed that a positive sense of self-efficacy and willingness to take risks will have been helpful.

In overall conclusion, therefore, the findings of this study of well motivated British language learners in France bears out the importance of the contextual/ structural factors identified by MurphyLejeune (2002) as distinctive of student sojourners. In the light of their short term commitment to France, their age, and their semi-independent adult status, it is clear why instant international networking with other Erasmus students is so attractive, and meets so many needs. On the other hand, their placements also offer structures which bring them into regular contact with locals and offer opportunities for gradually increasing social integration with time. Finally, their personal identities as language specialists, and increasing sense of self-efficacy as French language users, provide strong motivation to capitalise on these opportunities; however, willingness to take some social risks and to negotiate an unstable multilingual environment, plus possession of some form of desirable social capital seem also necessary, to make this happen. 


\section{References}

Aguilar Stewart, J. (2010). Using e-journals to assess students' language awareness and social identity during study abroad. Foreign Language Annals, 43(1), 138-158.

Badstübner, T., \& Ecke, P. (2009). Student expectations, motivations, target language use, and perceived learning progress in a summer study abroad program in Germany. Die Unterrichtspraxis / Teaching German, 42, 41-49.

Behrent, S. (2007). La communication interalloglotte. Paris: L'Harmattan.

Benson, P., Barkhuizen, G., Bodycott, P., \& Brown, J. (2013). Second language identity in narratives of study abroad. Basingstoke: Palgrave Macmillan.

British Council. (2005). Breaking the Barriers: 100 years of the language assistants programme 19052005. London: British Council.

Cook, H. M. (2008). Socialising identities through speech style. Bristol: Multilingual Matters.

Dewey, D. P., Bown, J., Baker, W., Martinsen, R. A., Gold, C., \& Eggett, D. (2014). Language use in six study abroad programs: An exploratory analysis of possible predictors. Language Learning, 64, 36-71.

Dewey, D. P., Bown, J., \& Eggett, D. (2012). Japanese language proficiency, social netowrking, and language use during study abroad: Learners' perspectives. Canadian Modern Language Review, 65, 111-137.

Dewey, D. P., Ring, S., Gardner, D., \& Belnap, R. K. (2013). Social network formation and development during study abroad in the Middle East. System, 41, 269-282.

Diao, W., Freed, B., \& Smith, L. (2011). Confirmed beliefs or false assumptions? A study of home stay experiences in the French study abroad context. Frontiers: The interdisciplinary journal of study abroad, 21, 109-142.

Dörnyei, Z. (2007). Research Methods in Applied Linguistics. Oxford: Oxford University Press.

European Commission. (2012). First European Survey on Language Competences: Final report. Brussels: European Commission.

Freed, B. F., Segalowitz, N., Dewey, D. P., \& Halter, R. (2004). The language contact profile. Studies in Second Language Acquisition, 26, 349-356.

Hernández, T. A. (2010). The relationship among motivation, interaction, and the development of second language oral proficiency in a study-abroad context. The Modern Language Journal, 94, 600-617.

lino, M. (2006). Norms of interaction in a Japanese homestay setting: toward a two-way flow of linguistic and cultural resources. In M. A. Dufon \& E. Churchill (Eds.), Language learners in study abroad contexts (pp. 151-173). Clevedon: Multilingual Matters.

Isabelli-García, C. (2006). Study abroad social networks, motivation and attitudes: Implications for second language acquisition. In M. A. DuFon \& E. Chruchill (Eds.), Language Learners in Study Abroad Contexts (pp. 231-258). Clevedon: Multilingual Matters.

Jackson, J. (2008). Language, identity and study abroad. London: Equinox.

Jackson, J. (2010). Intercultural journeys: from study to residence abroad. Basingstoke: Palgrave Macmillan.

Kadushin, C. (2012). Understanding Social Networks. Theories, Concepts, and Findings. Oxford: Oxford University Press.

Kalocsai, K. (2011). The show of interpersonal involvement and the building of rapport in an ELF community of practice. In A. Archibald, A. Cogo \& J. Jenkins (Eds.), Latest trends in English as a Lingua Franca research (pp. 113-138). Newcastle Upon Tyne: Cambridge Scholars Publishing.

Kinginger, C. (2008). Language learning in study abroad: case studies of Americans in France. Modern Language Journal, 92, 1-124.

Kinginger, C. (2009). Language learning and study abroad: A critical reading of research. Basingstoke: Palgrave Macmillan. 
Kinginger, C. (2010). American students abroad: negotiation of difference? Language Teaching, 43(2), 216-227.

Kinginger, C. (2011). Enhancing language learning in study abroad. Annual Review of Applied Linguistics, 31, 58-73.

Llanes, A., \& Munoz, C. (2013). Age effects in a study abroad context: Children and adults studying abroad and at home. Language Learning, 63, 63-90.

Martinsen, R. A., Baker, W., Dewey, D. P., Bown, J., \& Johnson, C. (2010). Exploring diverse settings for language acquisition and use: Comparing study abroad, service learning abroad and foreign language housing. Applied Language Learning, 20, 45-66.

Meier, G., \& Daniels, H. (2011). "Just not being able to make friends": Social interaction during the year abroad in modern language degrees. Research Papers in Education, 28(2), 212-238.

Milroy, L. (1987). Language and Social Networks: 2nd Edition. Oxford: Blackwell.

[AUTHOR 2]. (Forthcoming 2015). The development of social relations during residence abroad. Innovation in Language Learning and Teaching(Special Issue: Festschrift for Jim Coleman).

[AUTHORS]. (Forthcoming 2015). Placement type and language learning during residence abroad. In R. Mitchell, N. Tracy-Ventura \& K. McManus (Eds.), Social interaction, identity and language learning during residence abroad: European Second Language Acquisition (EuroSLA).

Murphy-Lejeune, E. (2002). Student mobility and narrative in Europe: the new strangers. New York: Routledge.

Papatsiba, V. (2006). Study abroad and experiences of cultural distance and proximity: French Erasmus students. In M. Byram \& A. Feng (Eds.), Living and studying abroad: Research and practice (pp. 108-133). Cleveland: Multilingual Matters.

Pellegrino Aveni, V. (2005). Study abroad and second language use. Cambridge: Cambridge University Press.

Schmidt-Rinehart, B., \& Knight, S. M. (2004). The homestay component of study abroad: three perspectives. Foreign Language Annals, 37(2), 254-262.

Scott, J. (2013). Social Network Analysis (Third Edition ed.). London: SAGE.

Teichler, U. (1997). The British involvement in European higher education programmes: Findings of evaluation studies on Erasmus, Human Capital and Mobility and Tempus The Thirtieth Anniversary Seminars (pp. 39-64). London: Society for Research into Higher Education.

Teichler, U., \& Ferencz, I. (2011). Student mobility data: Recent achievements, current issues and future prospects. In U. Teichler, I. Ferencz \& B. Wachter (Eds.), Mapping Mobility in Higher Education in Europe. Volume I: Overview and trends (pp. 151-177). Bonn: Deutscher Akademischer Austauschdienst.

Tinsley, T. (2013). Languages, The state of the nation: Demand and supply of language skills in the UK. Summary Report. London: British Academy.

Wiklund, I. (2002). Social networks from a sociolinguistic perspective: The relationship between characteristics of social networks of bilingual adolescents and their language proficiency. International Journal of the Sociology of Language, 153, 53-92. 